\title{
NUMERICAL SIMULATION OF STAPLES FOR EPIPHYSIODESIS
}

\author{
Halo T. ${ }^{*}$, Frydrýšek K. ${ }^{* *}$, Čepica D. ${ }^{* * * *}$, Skoupý O. ${ }^{* * * * *}$, Michal P.*****, Kraus Š. ${ }^{* * * * * * *}$, \\ Havlas V. ${ }^{* * * * * * * *}$, Kohut J."
}

\begin{abstract}
Bone staples are used for epiphysiodesis, which is orthopedic surgery correcting bone deformities, eg. varus or valgus deformity and length discrepancy. Stresses and displacements caused by interaction between staples and tibia are calculated via the finite element method. Determined values are used for bone staples assessment and clinical applications for treatment of patients.
\end{abstract}

Keywords: Biomechanics, Orthopedics, Epiphysiodesis, FEM, Staple.

\section{Introduction}

Epiphyseal stapling is a method of bone growth control using metal staples implanted into a specific part of children's bone to temporarily prevent its growth. The method was introduced by Walter Blount (Blount, 1949) and since then it became a common procedure of correcting mainly angular deformities (genu varum or genu valgum) of the knee in children. Growth of children or adolescent bone is provided mainly by physis, i.e. a cartilage structure near joints. Using the staple, we can restrain the physis either on both sides when correcting limb length discrepancy (i.e. 'epiphyseodesis') or on one side only when correcting angular deformities (i.e. 'hemiepiphyseodesis'). Unlike the method of permanent epiphyseodesis (Phemister, 1933), the epiphyseal stapling does not destroy the physis and therefore makes possible to restore the growth when the optimal correction is achieved. Although recently, the tension band technique introduced by Peter M. Stevens (Stevens, 2007), using a non-locking plate and two screws almost in the same position like staples, has slowly became a preferable alternative to stapling. Blount's original method still remains an effective means to treat lower limb deformities in adolescents.
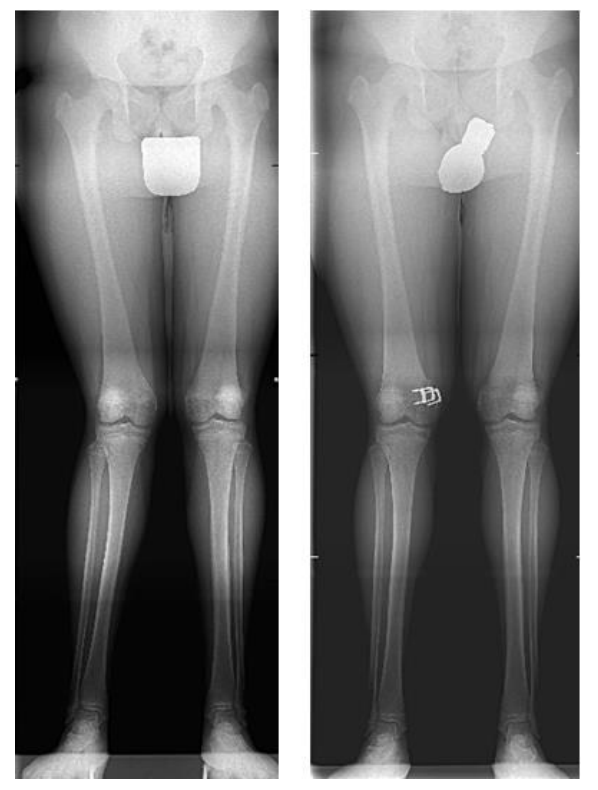

Fig. 1: Long radiogram of preoperative genu valgum and consecutive correction with staple.

* $\quad$ Bc. Tomáš Halo: Department of Applied Mechanics, VSB - Technical University of Ostrava, 17. listopadu 15/2172; 708 00, Ostrava; CZ, tomas.halo@vsb.cz

** $\quad$ Assoc. Prof., MSc. Karel Frydrýšek, PhD., ING-PAED IGIP: Department of Applied Mechanics, VSB - Technical University of Ostrava, 17. listopadu 15/2172; 708 00, Ostrava, CZ; \& University of Ostrava, Institute of Emengency Medicine, Syllabova 19, 703 00, Ostrava, CZ, karel.frydrysek@vsb.cz

*** Bc. Daniel Čepica: Department of Applied Mechanics, VSB - Technical University of Ostrava, 17. listopadu 15/2172; 708 00, Ostrava; CZ, daniel.cepica@vsb.cz

***** Bc. Ondřej Skoupý: Department of Applied Mechanics, VSB - Technical University of Ostrava, 17. listopadu 15/2172; 708 00, Ostrava; CZ, ondrej.skoupy@ vsb.cz

MSc. Pavel Michal: MEDIN, a.s., Vlachovická 619, 592 31, Nové Město na Moravě, CZ, pavel.michal@medin.cz M.D. Mgr. Šimon Kraus: Motol University Hospital, V Úvalu 84, 150 06, Praha 5, CZ, simon.kraus@ seznam.cz Prof. M.D. Vojtěch Havlas, PhD.: Department of Orthopaedics and Traumatology, $2^{\text {nd }}$ Faculty of Medicine, Charles University in Prague, V Úvalu 84, 15008, Prague 5, CZ, vojtech.havlas@lfmotol.cuni.cz

********* MSc. Jiří Kohut: Center of Advanced Innovation Technologies, VSB - Technical University of Ostrava, 17. listopadu 15/2172; 708 00, Ostrava; CZ, jiri.kohut@vsb.cz 
Apart from accurate diagnosis confirmed by radiogram of whole limb (Fig. 1), good timing of treatment is very important. The operational procedure includes short longitudinal incision through soft tissues over the physis and implantation of staple extraperiosteally with special instrument and under radiographic control (Fig. 2). The staple must bridge the physis but must not penetrate it to prevent its impairment (Fig. 3). The staples should not be restricting the physis longer than 2 years to prevent its permanent growth cessation. Other complications during

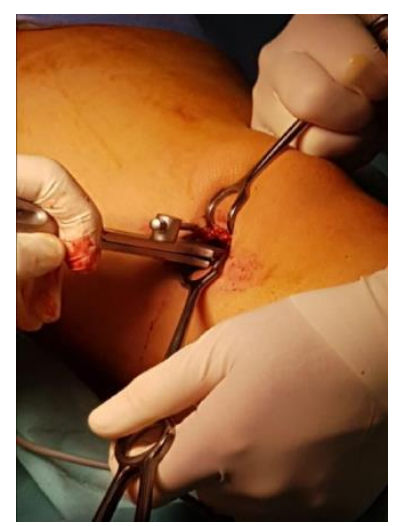

Fig. 2: Implantation of staples.
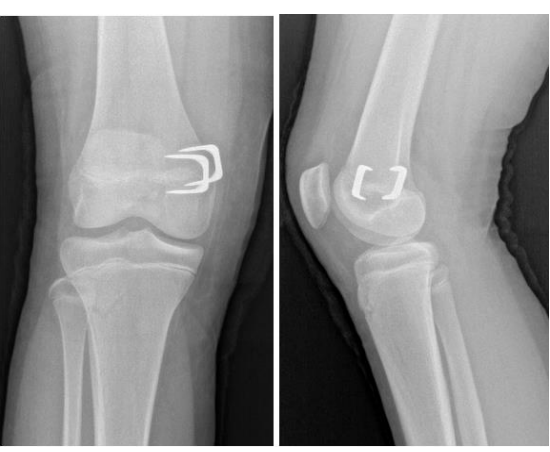

Fig. 3: Position of staples bridging the physis.

treatment can occur such as damaging the physis by imprecise staple implantation, mechanical failure of the staple (banding, rarely break) or staple migration. The last one is also the most often complication and disadvantage compared with tension band technique.

\section{Computational Model of Staples in Tibia}

To determine the behavior of bone staples used during treatment of Epiphysiodesis, a computer model of proximal part of tibia was created. This model was then split in the place of epiphyseal disk for further simulation of bone growth, see Fig. 4a. For this determination a set of two bone staples was chosen, for example see Fig. 4b. For more realistic approach (simulating staple migration), the contacts between bone staples and bone were set as frictional, with friction coefficient 0.2 acquired via educated guess. The reasoning behind this contact is the possibility of staple migration as mentioned before also due to staples flat surface. Provided models of bone staples from MEDIN a.s, were put into place as in real treatment, to slow the growth of epiphyseal disk see Fig. 4c.
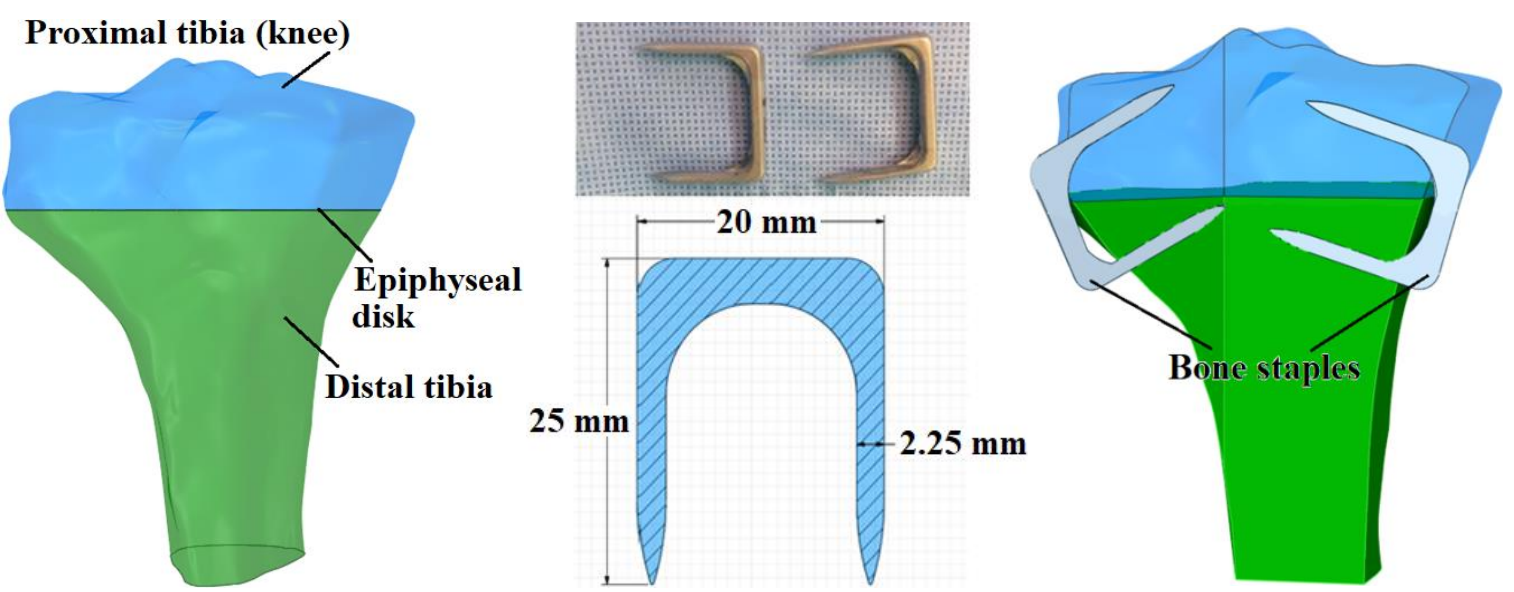

Fig. 4: a) Model of split tibia; b) Bone staples; c) Final model of split tibia with staples.

Material models of both bone and steel are assumed homogenous and isotropic, see Tab. 1 and (Drápala, 2018; Hlinka, 2016 and Losertová, 2016). The emphasis is put on bone staples. Hence, there is no need to divide tibia into cortical and spongiosal part (i.e. simplification).

Tab. 1: Mechanical properties of bone and steel.

\begin{tabular}{|c|c|c|c|}
\hline Material & Young's modulus [GPa] & Poisson's ration [1] & Yield stress [MPa] \\
\hline Cortical Bone & 0.161 & 0.3 & - \\
\hline Stainless steel 1.4441 & 183 & 0.33 & 690 \\
\hline
\end{tabular}




\section{Stress-Deformation Analysis}

Anatomical CAD model of tibia (acquired by 3D CT scan) with staples was then imported into Ansys Workbench 2019 R3 sw for further computations.

Bone model was meshed by quadratic tetra elements with average element size of $5 \mathrm{~mm}$. Bone staple models were meshed with average element size of $1 \mathrm{~mm}$. Element size was locally reduced to $0.5 \mathrm{~mm}$ in places with stress concentration.

The bone growth is simulated by internal tensile stress in bone acting as magnification (growth) of epiphyseal disc. Used boundary conditions are shown in Fig. 5. Two forces "B" and "C" of value $980.7 \mathrm{~N} \approx 100 \mathrm{~kg}$, which may occur after growth over time, due to the expansion of epiphyseal disc, were used as complex tensile forces (i.e. overloading) for simulation of bone growth.

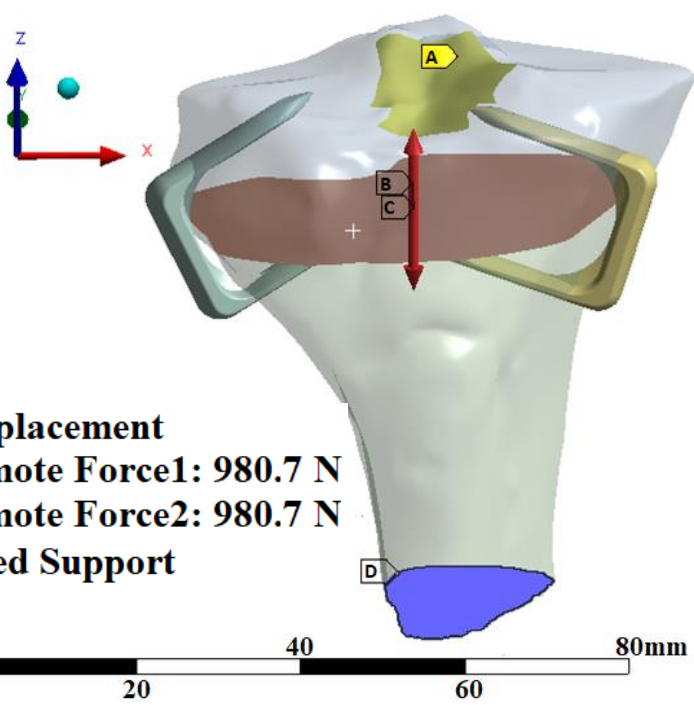

Fi. 5: Boundary conditions.

Displacement "A" acts as a weak simulation of a knee (for stabilization of numerical solution), therefore, in this case only allowing vertical movement in the direction $\mathrm{Z}$ of growth. Fixed support " $\mathrm{D}$ " acts as a definition of position of bone in space, not allowing any movement.

\section{Results}

From the results of stress-deformation analysis can be determined that the maximum stress occurs in sections of staples with radius and narrowed cross section, see Fig. 6 . The maximum stress is where the singularity occurs and therefore the evaluated maximum stress is taken from place identified as "DETAIL".
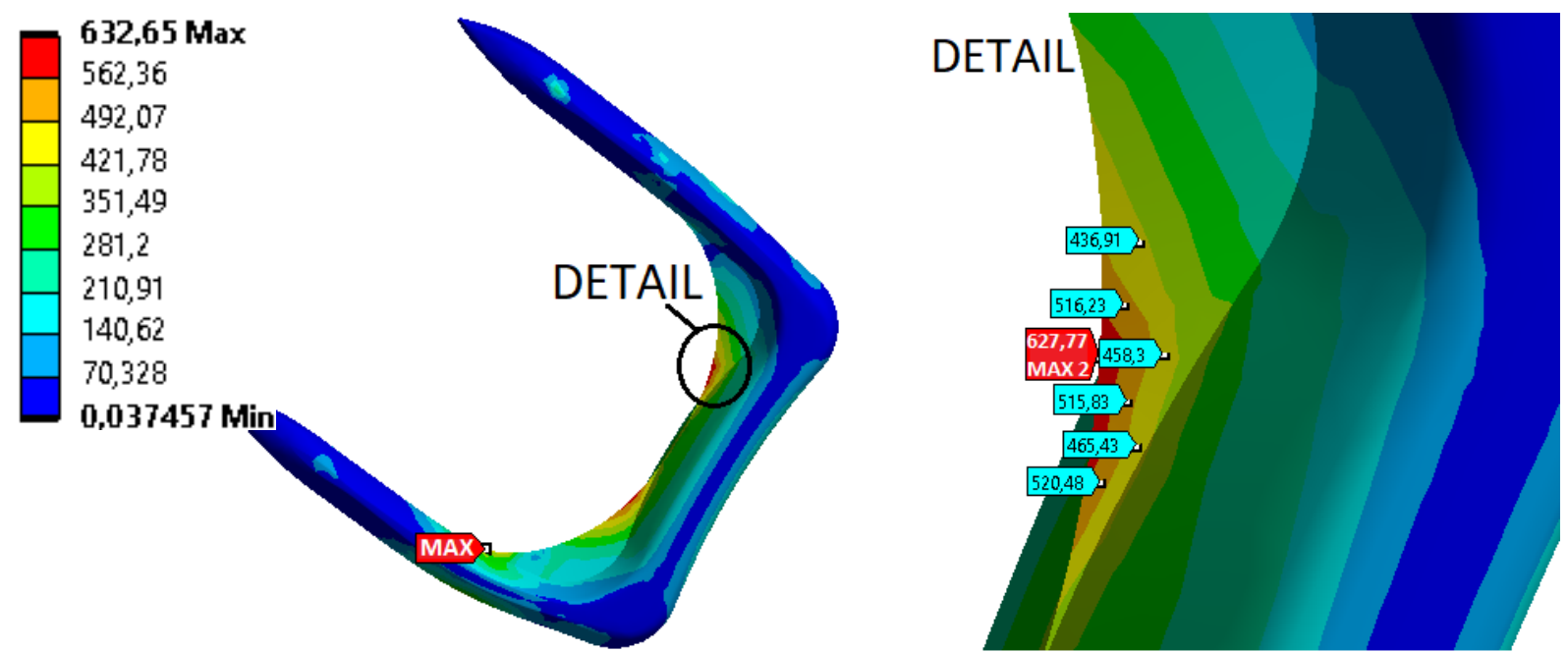

Fig. 6: Equivalent von Mises stress distribution and maximum stress in staple [MPa] (remote tensile forces $980.7 \mathrm{~N}$ ).
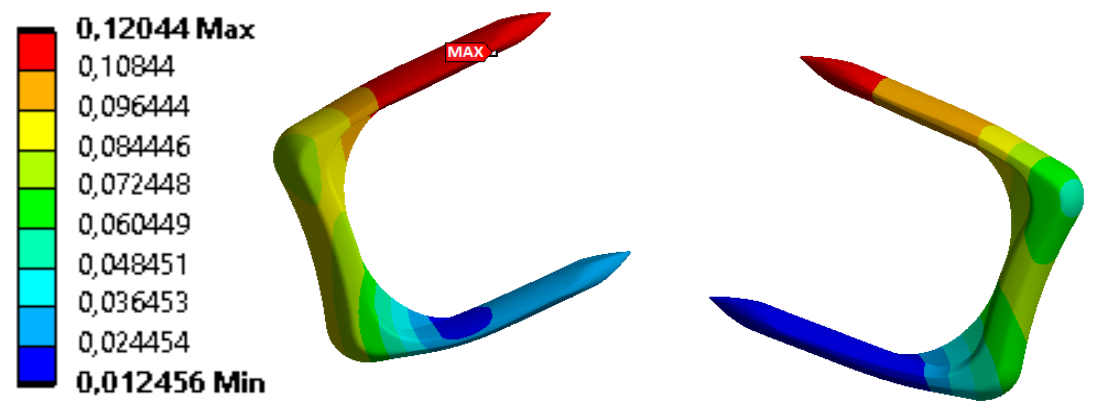

Fig. 7: Total displacement of bone staples [mm] (remote tensile forces $980.7 \mathrm{~N}$ ). 
Maximum displacement occurs on parts of bone staples which are located inside proximal part of tibia, due to growth of bone, which pushes this part upwards, see Fig. 7.

Bone was also analyzed and found sufficiently safe, because the bone tissue is practically intact around the bone staples. Therefore, there is no risk of any relevant mechanical damage (i.e. no fracture occurs).

\section{Conclusions}

In orthopedics, the bone staples are used to correct limb length discrepancy by implanting them into proper parts of tibia or other suitable bones. Evaluation of stresses and displacements in staples were done by the finite element analysis (ANSYS WORKBENCH $2019 \mathrm{R} 3 \mathrm{sw}$ ). Used models of staples were provided by MEDIN a.s. Bone growth was performed via overloading by estimated axial tensile force $980.7 \mathrm{~N} \approx 100 \mathrm{~kg}$ acting in epiphyseal disk.

Bone staples are made from medical grade stainless steel 1.4441. Minimum yield strength of this steel is $690 \mathrm{MPa}$. The calculated maximum equivalent von Mises stress in staple is $627.77 \mathrm{MPa}$. This stress is smaller than minimum yield stress even in the place of singularity in FEM model (i.e. safe state, recommended for medical treatment). Calculated total maximum deformation of staple is $0.125 \mathrm{~mm}$. Hence, because calculations were done for overloading, the staples and their applications are safe and suitable for medical applications.

Results may differ from person to person (anthropometry) and huge part of variance can be caused by staple placement.

For future endeavors, a heterogenous material (considering spongy bone and different mechanical properties in different parts of the bone) can be used and to verify these results, also an experiment should be done.

\section{Acknowledgement}

This work has been elaborated in the framework of projects FV40306 "Development of New Implants for Correction of Angular Pediatric Deformities in Sterile Design", CZ.02.1.01/0.0/0.0/17_049/0008441, CZ.02.1.01/0.0/0.0/17_049/0008407 and SP2020/23 "Numerical and Experimental Modeling to Support Solutions to Technical and Biomedical Problems"

\section{References}

Blount W.P, Clarke G.R (1949). Control of bone growth by epiphyseal stapling; a preliminary report. J Bone Joint Surg Am., 31A-3, pp. 64-478.

Drápala J., Kostiuková G., and Losertová M. (2018) Influence of heat treatment on microstructure and mechanical properties of SUS 316 alloy. $27^{\text {th }}$ International Conference on Metallurgy and Materials (METAL), Czech Republic, pp. 1527-1532.

Frydrýšek K., Jořenek J., Učeň O., Kubín T., Žilka L., Pleva L. (2012) Design of External Fixators Used in Traumatology and Orthopaedics - Treatment of Fractures of Pelvis and its Acetabulum, 5th International Conference on Modelling of Mechanical and Mechatronics Systems (MMaMS), Procedia Engineering, Vol. 48, pp. 164-173.

Hlinka J., Lasek S. (2016) Structure and Corrosion Properties of Electrochemically Treated Surface of 1.4301 (Aisi 304) Steel For Medical Applications, 25th Anniversary International Conference on Metallurgy and Materials (METAL), Czech Republic, pp. 1061-1066.

Hlinka J., Lasek S., Faisal N. (2017) Corrosion Properties of Anodized Titanium, Acta Metallurgica Slovaca, vol. 23, iss. 3, pp. 270-275.

Kalová M., Tomanec F., Rusnakova S., Manas L., Jonšta Z (2019) Mold Design for Rings of External Fixator, MM Science Journal, Iss. March, pp. 2739-2745.

Losertová, M., Štamborská, M., Lapin, J. and Mareš, V. (2016) Comparison of Deformation Behavior of 316L Stainless Steel and Ti6A14V Alloy Applied in Traumatology. METALURGIJA, vol. 55, iss. 4, pp. 667-670.

Phemister D. B (1933). Operative arrest of longitudinal growth of bones in the treatment of deformities. J. Bone Joint Surg. Am., 15, pp. 1-15.

Sabharwal S., Green S., McCarthy J. and Hamdy R. C. (2011) What's New in Limb Lengthening and Deformity Correction, J. Bone Joint Surg Am., 93, pp. 213-221.

Stevens P. M. (2007) Guided growth for angular correction: a preliminary series using a tension band plate. $J$. Pediatr. Orthop., 27, pp. 253-259. 